\title{
Who, Mies? Interrogating the Federal Center Courthouse and the Trial of the Chicago Seven
}

\author{
DAVID SHANKS \\ Syracuse University
}

\begin{abstract}
Among the many 'outputs' from architecture's 'black box' are the historical events that a building has witnessed. This essay interrogates Mies van der Rohe's Federal Center Courthouse through an analysis of the events of the Trial of the Chicago Seven, which was held there from 1969-70. In doing so, the essay reveals how Mies subverted the conventions of courtroom design, and consequently disrupted the precise rituals and power relationships that comprise the performance of jurisprudence. Specifically, Mies removed "the bar" from the courtroom space, which typically divides spectators from trial participants, producing a Brechtian estrangement of the courtroom and of trial procedure that played out in the various forms of misconduct that marked the theatrical trial.
\end{abstract}

I have no great admiration for special programs. ${ }^{1}$

-Mies van der Rohe

Nearly 50 years ago, the Trial of the Chicago 7 (U.S. v Dellinger et al) began at the Dirksen Federal Courthouse, one of three buildings designed by Mies van der Rohe that comprise the Federal Center in Downtown Chicago. At the time of the trial, the courthouse building was relatively new, having been completed only 4 years prior, and the two other Federal Center buildings were still under construction. In the preceding decades since his emigration from Germany, Mies had built extensively in his adopted hometown of Chicago, and was therefore a household name in the city. Indeed, Mies's name was invoked several times during the trial, by both the judge and the defendants. Over the course of the raucous and divisive trial, Mies was referred to alternately as, "the great architect", a source of prestige, and, "a Kraut", a megalomaniacal, oppressive figure. ${ }^{2}$

In his article, "The Postmodern Agenda," Charles Jencks cited the events of the Trial of the Chicago 7 as evidence to indict Mies and his brand of Modernism. In the trial, seven (originally eight) young men with prominent roles in organizing the "Festival of Life" protests against the Vietnam War at the 1968 Democratic National Convention in Chicago were charged with conspiracy to incite the violent riots that occurred there. The trial is notorious for the presiding Judge Julius Hoffman's bias against the defendants, whose convictions were a foregone conclusion. According to Jencks's argument, Mies and his architecture were complicit in the perpetration of the unjust trial. The, "reductivism, determinism, and mechanism," of Mies's, "black, quasi-fascist," work at the Federal Center was exemplified for Jencks by one particular interaction between the judge and Yippie Party co-founder Abbie Hoffman, in which the judge admonished the unruly defendant, "Get back in your place, where Mies van der Rohe designed you to stand!"3

Beyond Jencks's cursory examination, the relationship between the Trial of the Chicago 7 and the architecture of the courthouse which hosted it has not been studied in detail. Despite its unique status as Mies's largest built work for the U.S. Government, the Federal Center itself has been the subject of little critical attention. The purpose of this essay is therefore to re-interrogate Mies van der Rohe's designs at the Federal Center Courthouse vis-à-vis the evidence provided by the Trial of the Chicago 7, to see what there is to learn about the effects of Mies's architecture through a close look at the events that occurred there. More broadly, if we understand a trial as a series of precisely defined rituals, this essay will ask, what is the role of architecture in enacting those rituals, in encoding and reproducing the conventions of jurisprudence, or in enacting resistance to those conventions? What is the relationship between architecture and the performance of justice?

Judge Julius Hoffman was 74 years old at the time of the trial. With the 32 year-old Yippie co-founder and defendant Abbie Hoffman, the judge shared both a surname and a common Jewish heritage. The two Hoffmans sparred verbally throughout the trial, as Abbie loudly accused the judge of rampant bias against the defendants, and Judge Hoffman admonished Abbie to obey courtroom decorum. Abbie Hoffman frequently referenced their shared Judaism to insult the judge, for example telling him in Yiddish "Shanda fur de goyem," or, "Shame before the non-Jews," claiming that the judge was an embarrassment to the Jewish people for his bias. ${ }^{4}$ Abbie would routinely misbehave throughout the trial, pulling pratfalls and turning acrobatics to provoke the judge and disrupt the conduct of the trial. In the incident that Charles Jencks cited, Judge Hoffman invoked the name of the courtroom's architect in the effort to gain order in the court. Abbie, seizing on Mies's German background as a further opportunity to antagonize the judge, and to compare his own trial to the Nazi show trials of the 1930s, shouted, "Mies van der Rohe was a Kraut too!"5 In reference to the architecture itself, Abbie claimed, "This isn't a court; it's a neon oven!"6 comparing the gridded, illuminated ceiling of the courtroom to the cremation ovens of Auschwitz. 


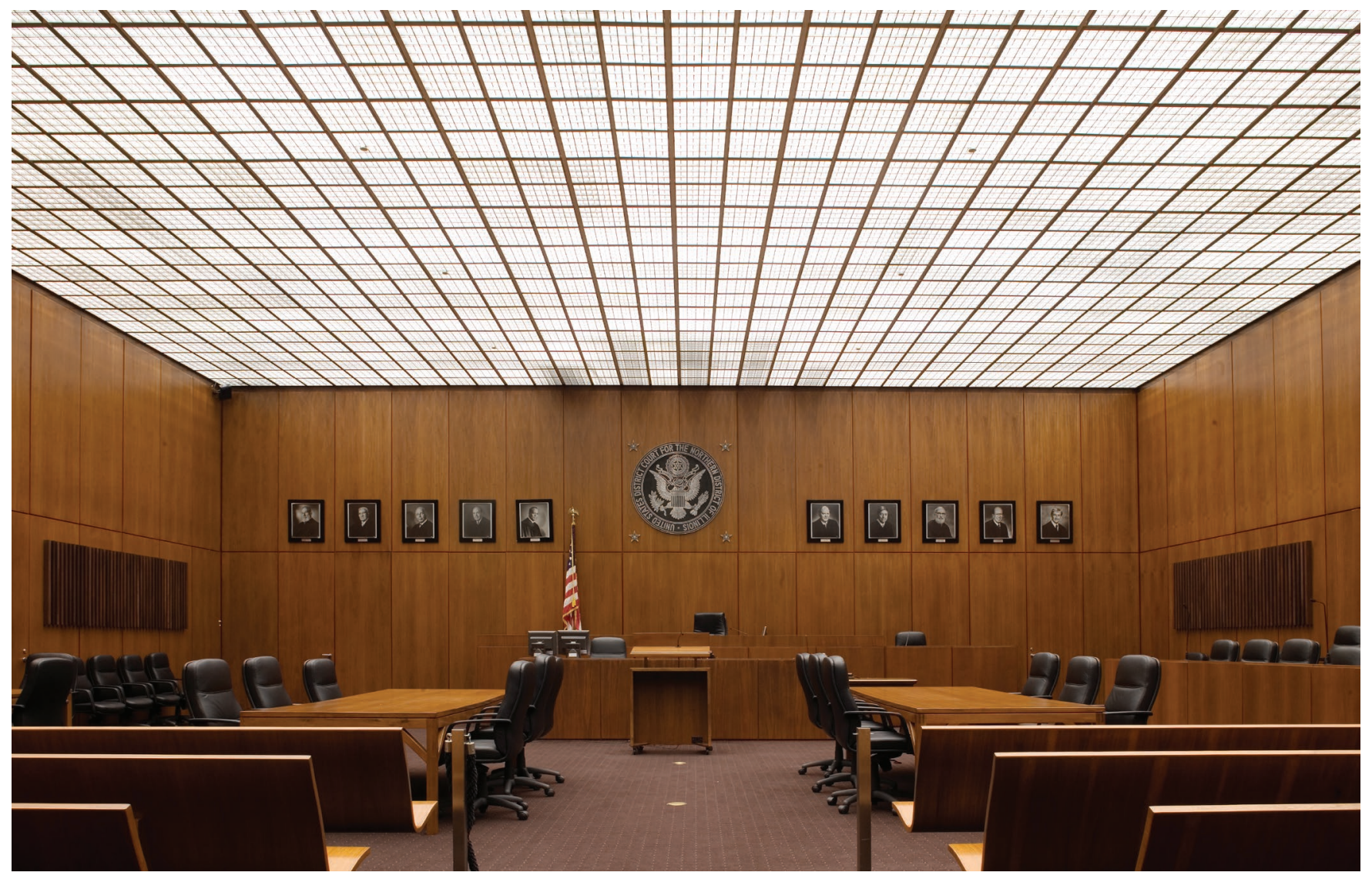

Figure 1. Ludwig Mies van der Rohe, courtroom interior, Dirksen Federal Courthouse, Chicago, 1964. (Library of Congress, Carol Highsmith, 2006.)

In this way, Mies van der Rohe and his work became proxies for the issues at stake in the conflict between Abbie Hoffman and the judge, a battle which was itself a microcosm of the broader generational strife that characterized the coming of age of the Baby Boomers in the American postwar. For Judge Hoffman, Mies's courthouse represented an example of progress, European sophistication, and modern authority. For Abbie Hoffman, the courthouse represented the fortification of an authoritarian state perpetrating an unjust colonial war, into which his generation was being sent to fight and die.

Franz Kafka's novel The Trial is an extended allegory for the citizen's experience of the law under an opaque, totalitarian regime such as that which Abbie Hoffman imagined the Federal Center to represent. In the novel, the protagonist Josef $\mathrm{K}$. is summoned to an unknown but omnipotent court to be tried for an unspecified crime. $K$. is given the address of the court where he is instructed to appear, but when he arrives, he finds himself strangely unable to identify the courthouse among the other buildings in the city:

"He had thought that he would recognize the building from a distance by some kind of sign, without knowing exactly what the sign would look like, or from some particular kind of activity outside the entrance. $K$. had been told that the building was in Juliusstrasse, but when he stood at the street's entrance it consisted on each side of almost nothing but monotonous, grey constructions..."7

Kafka's description of the anonymous presence of the court building in the city might be substituted for a description of Mies's courthouse at the Chicago Federal Center. The Dirksen Courthouse shows no outward sign of the function it contains, and does not clearly differentiate itself from other buildings in the city, or from the other buildings that comprise the Federal Center.

The 1905 Federal Building which the Federal Center replaced was, by contrast, clearly identifiable as a civic building in the city. Its Beaux-arts mélange of neoclassical features communicated the conventions of American civic architecture based in GrecoRoman ideals of republican democracy. Mies's courthouse includes none of these conventional signifiers; instead, the building is primarily referential of Mies's own preceding work. The architecture of the courthouse building follows the formula that Mies had established in previous tall-building projects including the Seagram office building in New York City and the Lake Shore Drive apartment towers in Chicago. Despite their disparate functions, these high-rises all share common 'Miesian' features, including similarly proportioned glass façades with expressed I-section window mullions, and triple-height clear-glass entry lobbies inset from the towers above. 


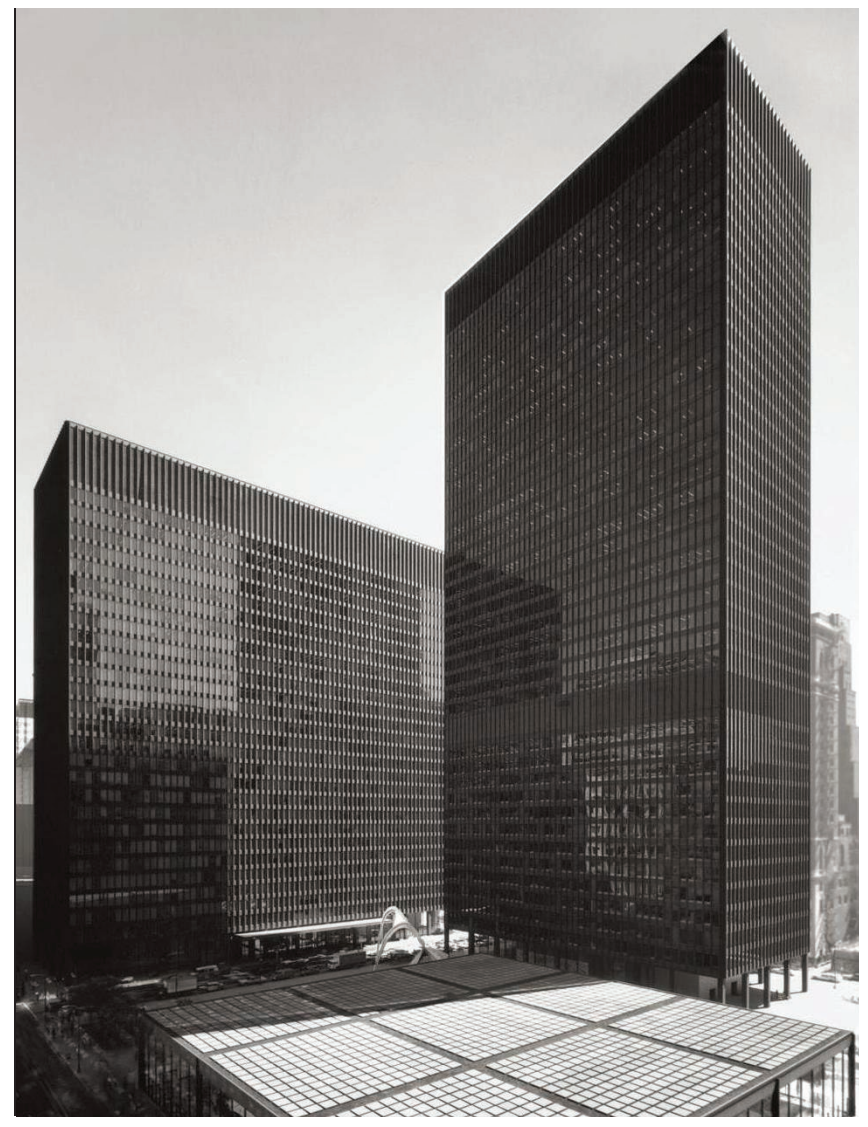

Figure 2. Ludwig Mies van der Rohe, Chicago Federal Center, Chicago, 1974. (Hedrich Blessing, public domain)

Early design studies produced by the MvdR office when they began work on the Federal Center project in 1959 show some potential for outward articulation of the courthouse program. In one iteration, the spandrel is eliminated on the curtain wall where it overlaps with the location of the double-height courtrooms. In this way, the presence of the courtrooms -- the specific program that makes the courthouse building unique compared to other building types -- would have been apparent from the surrounding street level, and the courthouse program would have been communicated to the city. "However, as with the IIT campus buildings, the principle of a universal rather than a specific solution was maintained, asserting Mies's desire to develop a common language rather than 'particular, individual ideas.' 'I have no great regard for special programs,' he said. Thus the façade of the courthouse building veils its program." ${ }^{\prime 8}$

In the built scheme, this 'special program' is nowhere indicated outwardly by the architecture of the building, whose façade is uniform throughout. The Kluczynski Federal Office building across Dearborn Street, which Mies also designed as part of the Federal Center project, is nearly indistinguishable from the courthouse except in its height and massing. The courthouse building seems to keep the function it was built to accommodate secret from the city, camouflaging the presence of the courts in direct opposition to the commonly held ideal of 'transparency' in the exercise of legal authority.

In The Trial, Joseph K. eventually discovers that the courtroom for which he has been searching is embedded within an otherwise anonymous tenement building, entered from within a private apartment. The disjunction between the private, domestic occupation of the tenement, and the expected public, civic occupation of the law courts is uncanny and disorienting to K. At Mies's Federal Center, the courtrooms are embedded in what appears in the city to be an unmarked office building. The courtrooms are all double-height spaces, held in the upper floors of the building, in the center of the plan surrounded by offices which occupy the space adjacent to the building façade. The disjunction between the building's use as a courthouse and its design typology as a high-rise office building is most apparent in the conflict between the large two-story courtrooms and the structural module of the building's steel frame.

The size of the courtrooms required by the building program was larger than the structural bay of the building could accommodate without interruption, both horizontally and vertically. This bay size -- 28'-0" x 28'-0" in plan and $12^{\prime}-0^{\prime \prime}$ floor to floor -- had been established based on the MvdR office's preceding experience in designing steel-framed office buildings such as the Seagram, whose structural module is nearly identical to that of the Dirksen Courthouse. ${ }^{9}$ At least two solutions were considered in order to accommodate the courtrooms within the structure: one option was to maintain the structural grid through the space of the courtrooms and to use the column and beam positions to locate the edges of upper-story mezzanine spaces for spectators; another option was to eliminate the columns and beams in the portions of the structural grid that overlapped the courtrooms, creating two-story voids in the structural frame.

Although the first option might have been more economical, the second was chosen for the built scheme. This required deep beams to span two bays above every courtroom so that each could be a clear-span space. Each courtroom occupies two full bays of the structure east-to-west and one-and-a-half bays of the structure north-to-south, as well as two stories of the structure vertically. Columns and beams are concealed in the thickness of walls and ceilings between the courtrooms such that the courtrooms themselves are clear, uninterrupted units of space. These double-height voids are cladded with walnut paneling on the four interior walls, grey carpeting on the floor, and a translucent, gridded ceiling above, concealing artificial lighting which is consistent throughout the room.

The design of the courtrooms minimizes the threshold between the audience and the trial proceedings within the space. The architecture creates no spatial subdivision of the courtrooms, and the decisions to void the structural grid at 
the courtroom positions and to not include a mezzanine, are in service of this idea: to maintain the indivisible unity of the courtroom space. This logic contradicts the longstanding tradition of courtroom design, which is predicated on the division of the space into two distinct zones -- one zone for spectators, and the other zone for trial participants. The two spaces are usually divided by what is called "the bar." The bar may take many architectural forms: it can be suggested by a change in ceiling height, ceiling material, lighting, floor material, floor height, etc.; it can be formed by the presence of a balcony above; but it most typically takes the form of a low balustrade with a gate in it, capped by a wooden bar.

The courtrooms in the 1905 Federal Building which the Federal Center replaced, for example, contained a typical bar to spatially divide trial spectators from trial participants. There, the zone of the courtroom past the bar and the zone behind the bar were architecturally differentiated beyond the physical presence of the bar itself. The litigators' zone was wrapped by an interior façade of paired Corinthian pilasters which faced out to the spectators' zone. The division between the zones was further emphasized by two arched entrances at either side of the courtroom in front of the bar, which formed a kind of transept across the primary aisle of the space.

In law, the bar has major significance: it stands in metonymically for the legal profession as an institutional whole. A lawyer must be "admitted to the bar" in order to practice law, and the licensing examination for aspiring lawyers is known as the Bar Exam. The function of the bar in the courtroom is to establish the hierarchical distinction between those whose speech is vested with juridical authority and those whose speech is not. When a witness or juror is admitted past the bar into the zone of litigation, that person is required to say an oath in order to gain passage and have their speech thereby legally vested. Anyone who is physically past the bar is therefore authorized to speak before the law.

Kafka punctuates The Trial with a brief parable titled which is told to Joseph $\mathrm{K}$. in a cathedral by a priest who reveals himself to be an employee of the obscure court in which $\mathrm{K}$. is being tried:

"Before the law sits a gatekeeper. To this gatekeeper comes a man from the country who asks to gain entry into the law. But the gatekeeper says that he cannot grant him entry at the moment. The man thinks about it and then asks if he will be allowed to come in sometime later on. 'It is possible,' says the gatekeeper, 'but not now.' The gate to the law stands open, as always, and the gatekeeper walks to the side, so the man bends over in order to see through the gate into the inside. When the gatekeeper notices that, he laughs and says: 'If it tempts you so much, try going inside in spite of my prohibition. But take note. I am powerful...'"10
Where Kafka's parable exaggerates the difficulty in crossing the threshold, in Mies's courtrooms at the Dirksen Courthouse, this threshold is radically minimized, reduced to a pair of small chromed-metal stanchions, between which a rope can be slung. The bar is objectified into a distinct, removable thing, and the architecture which surrounds it does not conform to its presence either spatially or materially. Any other implication of a subdivision of the space, such as a change in lighting, material, or level is eschewed. Mies's minimization of the bar and consequent elision of the typically separate zones of litigators and spectators is both peculiar and consequential, as the following section of the essay will explore.

The 1968 DNC protests and the trial that followed were notoriously theatrical. Indeed, Abbie Hoffman, in the leadup to the DNC, had explicitly stated his theatrical intentions for the Festival of Life: "it's all conceived as total theater, with everyone becoming an actor." ${ }^{11}$ Hoffman and his fellow Yippies intended to use absurd and unpredictable nonviolent behavior to provoke the police into actions which would embarrass and undermine them. Hoffman brought this strategy of 'total theater' to the courthouse during his trial, performing cartwheels for the cameras outside the Dirksen Courthouse, and dancing around and standing on his head inside the courtroom:

Specification 21: On April 4, during the cross-examination of the witness Phillips, Mr. Kunstler was examining the witness concerning the witness's concept of how hippies dress. During that incident, Mr. Hoffman got up and danced around, lifting his shirt and baring his body to the jury, and engaged in antics designed to make light of the testimony of the witness. The incident is reported as follows:

Q: You are the first one that hasn't identified him. (Hoffman.) This is Mr. Hoffman over here.

(There was laughter in the courtroom.)

THE COURT: Let the record show that Mr. Hoffman stood up, lifted his shirt up, and bared his body in the presence of the jury - -

MR. KUNSTLER: Your Honor, that is Mr. Hoffman's way.

THE COURT: - - dancing around.

(There was laughter in the courtroom.)

MR. KUNSTLER: Your Honor, that is Mr. Hoffman's way.

THE COURT: It is a bad way in a courtroom. ${ }^{12}$ 


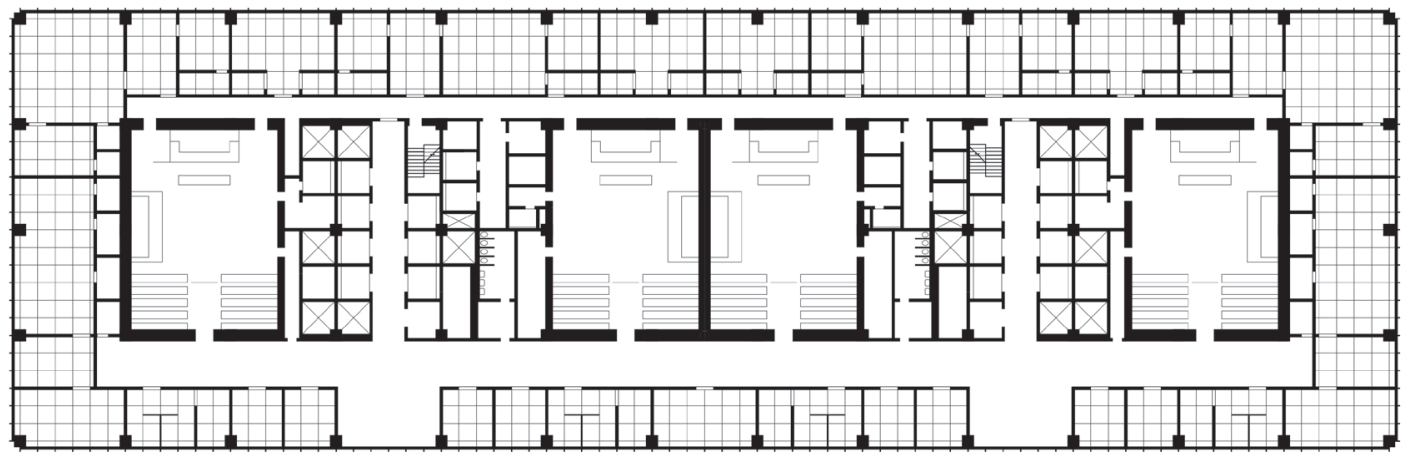

Figure 3. Plan of the Dirksen Federal Courthouse. (Produced by the author.)

In another instance, Abbie and fellow Yippie defendant Jerry Rubin appeared in court dressed in justice's robes. This had the intended effect of antagonizing Judge Hoffman, who forcefully demanded that the two remove the robes. They complied, only for Abbie to reveal that underneath the judge's robes he was wearing a Chicago Police uniform. As Harry Kalven wrote in the introduction to his book Contempt, a transcript of contempt citations against the defendants, "The heightened sense of interruption that these tactics seem to have engendered is perhaps attributable to... the presence of 'a studio audience' which often interacted with the defense, producing applause or occasions on which spectators were ordered removed from the courtroom." ${ }^{\prime 13}$

It follows, therefore, to examine the design of the courtrooms at the Dirksen Courthouse relative to the conventions of the theatre. The bar which typically separates spectators from trial participants in a courtroom, and is conspicuously missing in Mies's courtrooms, is analogous to the proscenium in a theater, a plane implied by the elevated stage and its surrounding frame that separates the play's actors from its audience. The proscenium forms the so-called "fourth wall" of the theater; an action which breaches the division is often called "breaking the fourth wall." In the "Epic Theater" of German avant-garde playwright Bertolt Brecht, this technique of breaking the fourth wall of the theater, uniting the audience with the scene, 'with everyone becoming an actor,' was essential to produce in the audience what Brecht termed the Verfremdunseffekt or "estrangement effect." In this way, the audience is discouraged from suspending their disbelief, passively consuming the action of the play, and is instead intended to become aware of its artificiality, and gain a critical distance from the drama.

Many of Brecht's Epic Theater plays dramatize trials or include dialectical dramas which are trial-like, intending, in Brecht's own words, "to teach the spectator to reach a verdict."14 The verdict reached by the audience of Brecht's plays is not, according to Fredric Jameson's argument in Brecht and Method, reserved to the specifics of the dramatic situation at hand, but expands to encompass the nature of judgement itself. Jameson likened Brecht's plays to casus, one of literary theorist Andre Jolles's nine 'simple forms' of story-telling. In Brecht's trial-like plays, "the casus represents a judgement about judgement as such: the passage of a sentence not with respect to a given norm but, rather, with respect to the very validity of norms as such, in juxtaposition with each other... This is the sense in which the Brechtian revolutionary casus does not reaffirm the norm or the Law but, rather, challenges it."15

Mies's designs for the courtrooms at the Federal Center are analogous to Brecht's Epic Theater techniques, and the theatrics of the Trial of the Chicago 7 are analogous to the casus which these techniques produce. Mies degrades the fourth wall of the courtroom, which separates the trial spectator from the trial participant, thereby diminishing the hierarchy between viewers and viewed, between subject and object, between those whose have "passed the bar" and those who have not. Through Mies's techniques of minimization, omission, and erasure, the courtroom is made strange in comparison to the conventional model, and therefore vulnerable to criticism. To the Trial of the Chicago 7's defendants, "the proceedings were an opportunity to put the system on trial,"16 and the estranged Brechtian context of their trial was, in a way they could not have predicted, sympathetic to their aims.

Near the end of the trial, during the contempt proceedings which followed his conviction for conspiracy to incite riot, Abbie Hoffman once again invoked Mies and his architecture when addressing the judge:

I called this place a neon oven. A neon oven in a stainless steel cuckoo nest, designed by your friend Mies van der Rohe. I might add he died right after he built this; it kind of killed him, building a building in which he had to put men away in prison and perhaps into death houses. ${ }^{17}$

As before, Abbie aligned Mies with Judge Hoffman and the prosecution of the trial. However, this time, he reserved some compunction for the architect. Abbie supposed that Mies may have felt such guilt at creating a building to serve as the seat of an unjust power that he actually died as a result. 


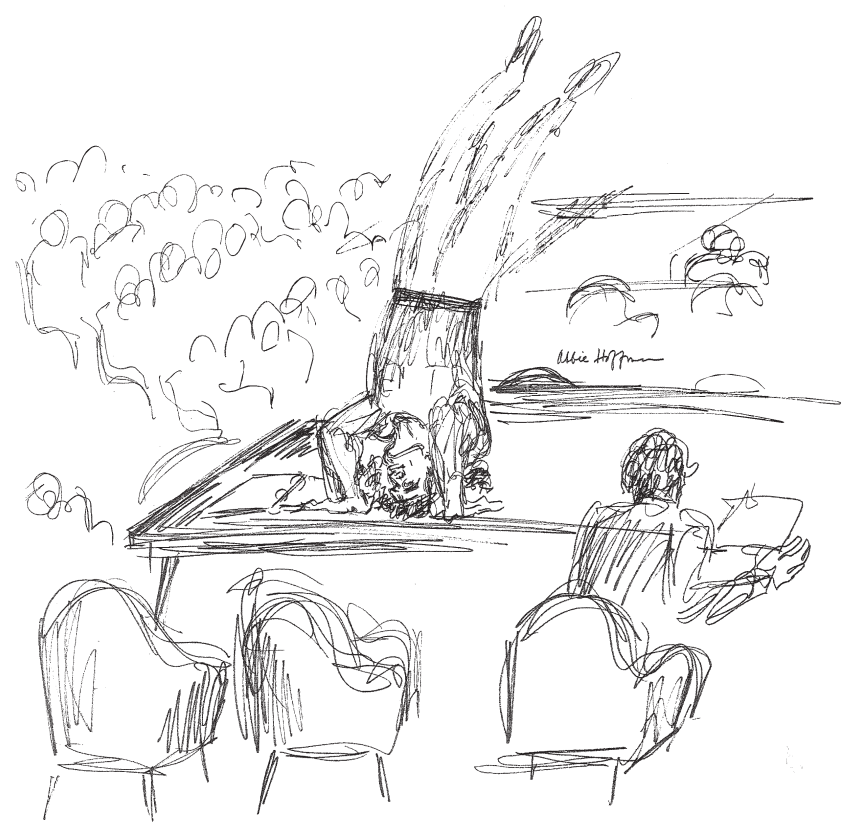

Figure 4. Drawing of Abbie Hoffman doing a handstand during the trial. (Verna Sadock)

Looking closely at the design of the courthouse building, we can locate this compunction in Mies's architecture. The 'special program' of the Dirksen Courthouse -- the courtrooms in which people are put away, "in prison and perhaps into death houses," -- is withheld from appearing in the city. In this way the federal authority of the court is not transmitted in the city through any pre-existing set of architectural conventions, a radical departure from the Beaux-Arts Federal Building which preceded Mies's design. Although the reticence of the courthouse with regard to its program can be read as producing a kind of Kafka-esque opacity of government power, it can also be understood as an attempt on Mies's part to resist the role of architecture as a medium for broadcasting and perpetuating that power.

While we may typically expect architectural form to follow the pre-existing functions of the program which it is built to contain -- to formally, spatially, and materially encode the already expected norms and procedures of the established culture -- Mies instead operates through refusal, elision, and intentional omission to strip away those conventions, making space for something else to emerge. Mies resists architecture's role in the reproduction of conventional rituals and protocols of power. By physically instantiating a seat of federal authority, Mies is inevitably to some degree complicit in the activities of that authority. However, the compunction that Mies demonstrates in this act of instantiation, minimizing the appearance of the seat of power and the hierarchies that are produced vis-à-vis that appearance, manifests a capacity for resistance to the authority instantiated therein.

The specific nature of that resistance is, however, left vague in Mies's courtrooms. Mies's voiding of juridical conventions in the courtroom opens up space for new manners of courtroom performance, but his architecture does not privilege any particular kind of performance over another. It minimizes the existing convention, but does not diagram a specific replacement. In A Thousand Plateaus, Gilles Deleuze argued that the spatial diagram of the Panopticon prison, as famously analyzed by Michel Foucault, is an 'abstract machine' which, "imposes a particular form of conduct on a particular multiplicity." ${ }^{18}$ Mies's un-diagrammed courtrooms at the Dirksen Courthouse do the opposite: they open up space for a variety of forms of misconduct. With this understanding of Mies's courtrooms, Charles Jencks's argument for the "determinism" of the Federal Center, based on Judge Hoffman's command to Abbie Hoffman, "Get back in your place where Mies van der Rohe designed you to stand!" is difficult to comprehend. There is no particular place in the courtroom where Mies designed for a defendant to stand, only a singular, undivided unit of space. In this sense, perhaps the most appropriate response to the judge's command was found in the 'bad way' that Abbie Hoffman behaved in the courtroom, turning a handstand on one of the solid walnut tables, orienting his feet up toward the gridded illuminated ceiling of the 'neon oven', occupying, if only for a moment, Mies's 'universal space' rather than a definite position prescribed by procedural norms. ${ }^{19}$

\section{ENDNOTES}

1. Ludwig Mies van der Rohe, interview with John Peter, 1955, quoted in Phyllis Lambert, "Federal Center, Chicago," in Mies in America (Montreal: Canadian Center for Architecture, 2001), 409.

2. The article "Judge Interrupts Trial to Chew Out Attorney," Desert Sun, November 19, 1969, quoted Judge Hoffman as scolding defense attorney William Kunstler for improperly standing at the lectern: "There's a great architect, Mr. Mies van der Rohe, who designed this building and that lectern. It is a lectern, not a leaning post. Now get behind it." For "Kraut," see United States v. Dellinger, et al., 472 F.2d 19, 803 (N.D. III. 1972)

3. Charles Jencks, The Post-Modern Reader (London: Academy Editions, 1992), 12.

4. United States v. Dellinger, et al., 472 F.2d at 622.

5. United States v. Dellinger, et al., 472 F.2d at 803.

6. United States v. Dellinger, et al., 472 F.2d at 847.

7. Franz Kafka, The Trial, trans., David Wyllie (New York: Dover Publications, 2009), 41.

8.Phyllis Lambert, "Federal Center, Chicago," in Mies in America (Montreal: Canadian Center for Architecture, 2001), 409.

9. According to Peter Carter's book Mies van der Rohe at Work (Washington: Praeger Publishers, 1974), the structural module at the Seagram Building is precisely $27^{\prime}-9$ " $\times 27^{\prime}-9$ " $\times 12^{\prime}-0$."

10. Kafka, The Trial, 254-55.

11. "Chicago 10: The Yippies," Public Broadcasting Service, accessed July 22, 2018. http://www.pbs.org/independentlens/chicago10/yippies.htm.

12. United States v. Dellinger, et al., 472 F.2d at 622-24. 
13. Harry Kalven, Contempt (Chicago: Swallow Press, 1970), xxvii.

14. See Yasco Horsman, "Brecht on Trial," in Theaters of Justice (Stanford: Stanford University Press, 2011), 91-132.

15. Frederic Jameson, Brecht and Method (New York: Verso, 1998), 119-20.

16. Adam Cohen and Elizabeth Taylor, American Pharaoh: Mayor Richard J. Daley (New York: Warner Books, 2000), Google Books, accessed October

31, 2018. https://books.google.com/books/about/American_Pharaoh.

html?id=nGem2g467GAC\&redir_esc $=y$.

17. United States v. Dellinger, et al., 472 F.2d at 877.

18. Giles Deleuze and Félix Guattari, $A$ Thousand Plateaus (Minneapolis: University of Minnesota Press, 1987), 442.

19. I am indebted to Professor Timothy Hyde for this observation. 